\title{
Intelligent Data Processing Technologies for Resource Management in Manufacturing Scheduling
}

\author{
Murat Guzairov \\ Ufa State Aviation Technical University \\ Ufa, Russian Federation \\ guzairov@ugatu.su
}

\author{
Nafissa Yussupova \\ Ufa State Aviation Technical University \\ Ufa, Russian Federation \\ yussupova@ugatu.ac.ru
}

\author{
Dmitry Rizvanov \\ Ufa State Aviation Technical University \\ Ufa, Russian Federation \\ ridmi@mail.ru
}

\begin{abstract}
The paper deals with the problem of resource management in manufacturing scheduling. The authors consider the problem definition of resource management using ill-formalized constraints of non-numerical nature ("semantic domain constraints"). It is suggested to use intelligent data processing technologies resource management in manufacturing scheduling. This technology is based on multiagent approach. The main idea is to represent the process of solving the task of resource management as a sequence of negotiations or communication interactions of agents. The behavioral algorithms for the main agents was developed: "detail", "operation", "resource".
\end{abstract}

Keywords-resource management, manufacturing scheduling, decision making, multi-agent approach, Industry 4.0

\section{INTRODUCTION}

In 2011, a number of German industrialists and economists predicted the forthcoming fourth industrial revolution. It is also called "Industry 4.0" [1]. The authors of the idea believe that if the third industrial revolution provoked the development of information technologies, the second - electrification, and the first - the invention of the steam engine, now a new round of development will be caused by the deep integration of information technologies into production processes. The fourth revolution will be based on a change in the principle of organization of production processes. In fact, it means a new generation of systems, strategies and technologies to optimize labor and reduce costs.

According to the founder and chairman of the World Economic Forum, Professor Klaus Schwab, with the new industrial world order, machines and products will learn to "communicate" with each other, and human participation in the production process will be minimized [2].

The industrial concept "Industry $4.0 "$ is a global, complex, multi-level organizational and technical system based on the integration into a single information space of physical operations and related processes consisting of 6 subsystems:

\section{PLM (Product Lifecycle Management). \\ 2. Big Data.}

\section{SMART Factory.}

4. Cyber-physical systems.

5. Internet of Things (IoT).

6. Interoperability.

One of the most important subsystems that consider the organization and alignment of the production process, taking into account available resources, is Smart Factory. The concept of Smart Factory is based on the seamless connection of individual stages (operations) of the production process, from the stage of product design and planning of the production resources use.

The efficiency of the production organization depends primarily on the quality of production scheduling, the rational resource allocation and the uniform loading of production capacity in the manufacture of parts.

Currently, there are MRP, ERP and MES systems on the software market for solving problems of managing resources in production [3-7], among which the most well-known were developed by SAP, Oracle, Baan, PeopleSoft, JD Edwards and etc. The presented software allows to solve a wide range of tasks related to resource management. They can operatively construct the production schedule and monitor it. However, the task of resource management in scheduling production is not fully solved.

\section{PROBLEM DEFINITION}

An industrial enterprise is a complex socio-economic system. In a fast changing environment a model of complex socio-economic system must meet the following requirements (see fig.1): the need to respond quickly to changes and adaptability of model.

Significant influence on the management and allocation of resources have the following characteristics of resources: heterogeneity, mobility, interoperability, complexity, finiteness and uniqueness.

In our research we consider the following types of resources - material, financial, labor, energy and time. 


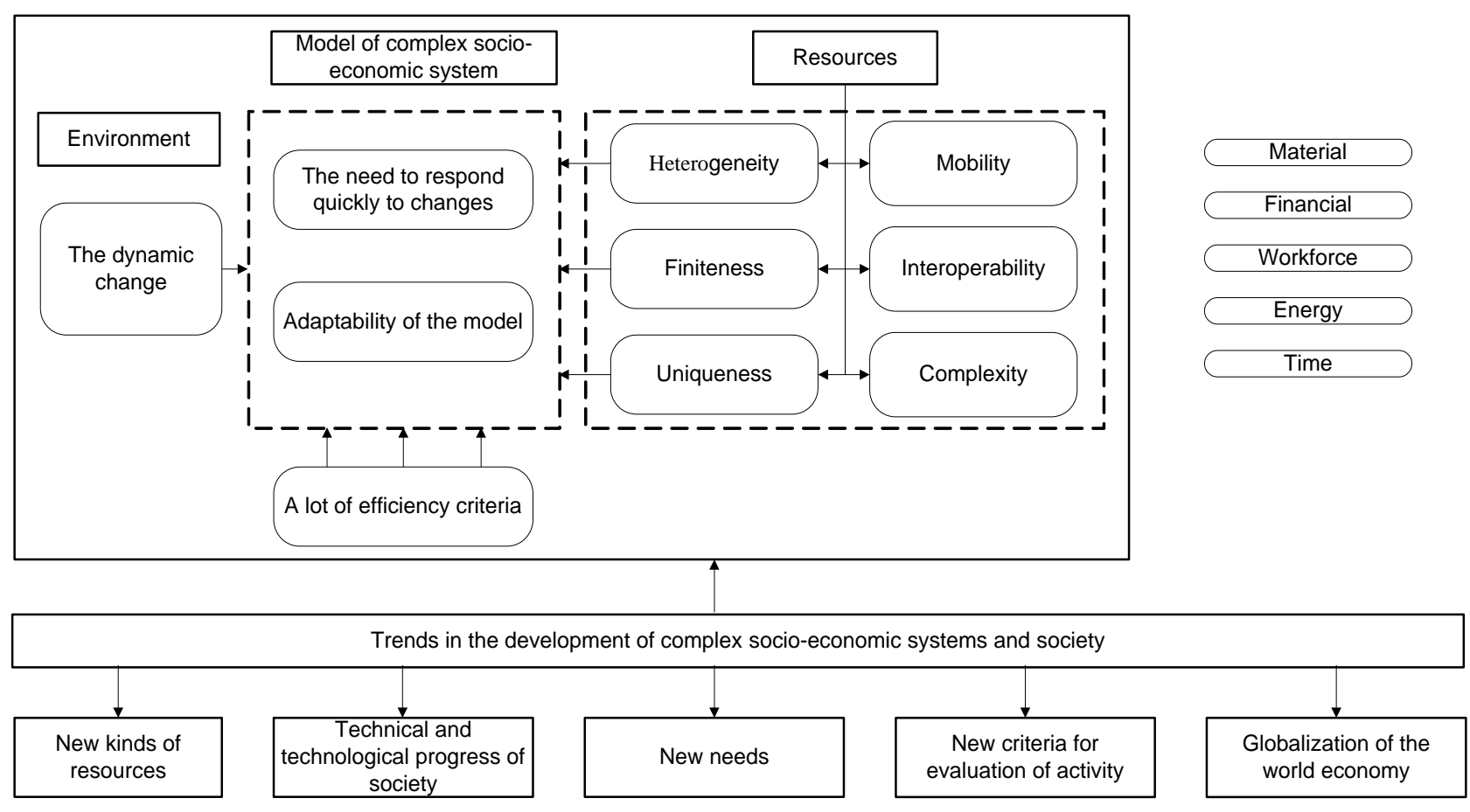

Fig. 1. Features of resource management in complex socio-economic system

To assess the efficiency of resource allocation there may be many criteria, some of which may be contradictory. The society, acting as the external environment for the complex socio-economic system, is not only subject to change, but developing. Technical and technological progress of society leads to the fact that there are new kinds of resources, new needs arise, the new criteria for evaluation of activity are formed.

A plan of parts' manufacturing is represented by a sequence of jobs for the parts manufacturing using concrete equipment with the use of a particular instrument, by concrete workers in a specific time. This plan should provide manufacturing of the required number of parts using the existing equipment, machines, tools and workers, etc. The result of the planning process will be a plan that defines the time slots of all jobs on every concrete machine (equipment) by every concrete worker for each concrete part. The goal of this plan is to allocate the available limited resources (machines, equipment, tools, and workers) for the manufacture of parts for a certain period (shift, day, week, month, year, etc.).

\section{MULTI-AGENT APPROACH TO RESOURCE MANAGEMENT}

It is proposed to use multi-agent technologies and knowledge engineering for resource management.

Application of intelligent technologies makes possible in principle to a new formulation of the problem and consider ill-formalizable information. This fact allows you to build models that more accurately reflect the properties and interactions of the real world. This improves the quality of decision making by the adequacy of the models and rapid response to any changes in the environment.

The proposed approach takes into account the individual characteristics of the simulated real-world objects and semantic constraints of subject areas and can provide acceptable resource allocation in a set of criteria. It provides for the decision maker, the necessary, reliable and valid information. In addition, the system built on the basis of these principles, can respond quickly to any contingency.

It is suggested to distinguish two basic types of agents [8]:

- Agents - Resource;

- Agents - Consumers of Resources.

The agents of multi-agent system for resource allocation play the role of consumers and/or suppliers of resources, as well as the resources themselves. The agents are forced to interact and negotiate with each other to solve the problem of resource allocation. Such interaction is simulated by the communication process.

The general scheme of resource allocation problem solving can be represented as a generalized algorithm in Fig. 2.

The agents of multi-agent system for resource allocation play the role of consumers and/or suppliers of resources, as well as the resources themselves.

Any ill-formalized semantic constraints are presented by an ontological knowledge base which is available to each agent. In addition, the agent's knowledge base is used to describe the criteria that reflect the acceptability of the resource allocation and take into account the individual characteristics of the simulated real-world objects. The agents determine the admissibility and acceptability for their decisions based on personal knowledge when negotiating.

The agents are forced to interact and negotiate with each other to solve the problem of resource allocation. The communication process simulates such interaction. 


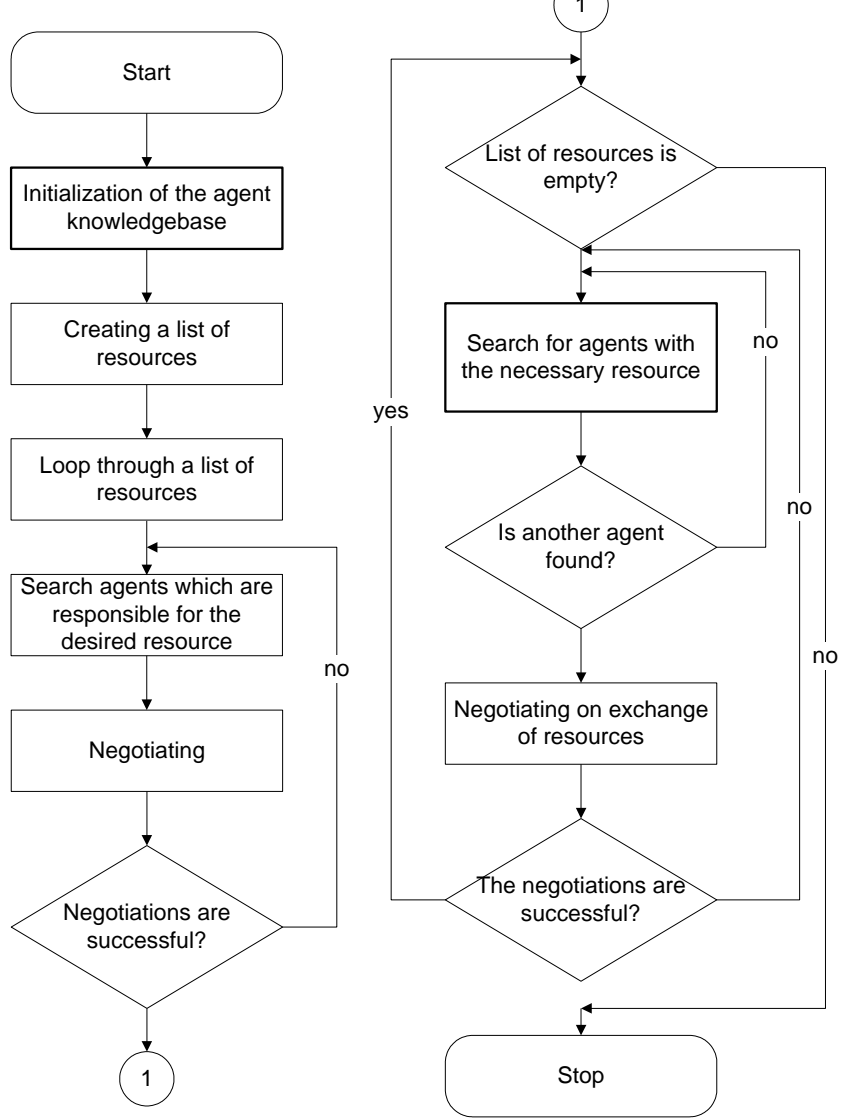

Fig 2. General algorithm of resource allocation

According to the developed decision support methodology for resource management in complex systems [9] the resources will be workers, machines, equipment, tools, etc., and consumers of resources will be parts and operations.

In most cases, the problem of resource allocation is a global performance criterion that must be achieved by an appropriate allocation of resources. Then the behavior of the agents can be considered as cooperative, because only the account of mutual interests can solve the problem. At the same time, each agent can have its own local criteria to determine the effectiveness of the solution for a particular agent

For example, one solution may be preferable over an other one based on the use of local performance measures, even though they can be exactly the same in terms of overall efficiency criterion.

The global goal of resource and resource consumers' agents is to minimize the time of manufacture of all parts:

$$
\max _{i}\left(T_{i l m_{1}}^{B}+\sum_{j=1}^{E_{i}}\left(\frac{\left(L_{i j}+L_{i j}^{\text {PBefore }}+L_{i j}^{\text {PAfter }}\right)}{f(M X, S, i, j)}+L_{i j}^{P W}\right)\right)-\min _{i}\left(T_{i 1 m_{1}}^{B}\right) \rightarrow \min
$$

Fig 3. Behavioral algorithm of agent «detail»

$T_{i j m}^{B}$ is the moment of the beginning of the execution of a set of resources $m$ operation $j$ for the manufacture of part $i$; $E_{i}$ is the number of operations required to manufacture part $i$;

$L_{i j}$ is the normative time for performing operation $j$ of part $i$; $L_{i j}^{\text {PBefore }}$ is the duration of idle parts before the start of operation $j$ for the manufacture of part $i$, associated with the preoperative adjustment, tuning;

$L_{i j}^{P A f t e r}$ is the duration of idle parts after the end of operation $j$ for the preparation of part $i$, associated with postoperative changeover;

$f(M X, S, i, j)$ is a function that takes into account the performance of the resources used to perform operation $j$ in the manufacture of part $i, M X$ is the matrix of resource assignment, $S$ is the matrix of resource productivity;

$L_{i j R_{i j}}^{P W}$ is the duration of idle time associated with waiting for the necessary resources to perform the operation $j$ of part $i$.

Local resource agents' goal is maximizing in-come, improving skills, etc.

The behavioral algorithms for the main agents was developed: "detail", "operation", "resource" (see Fig. 3, 4, 5).

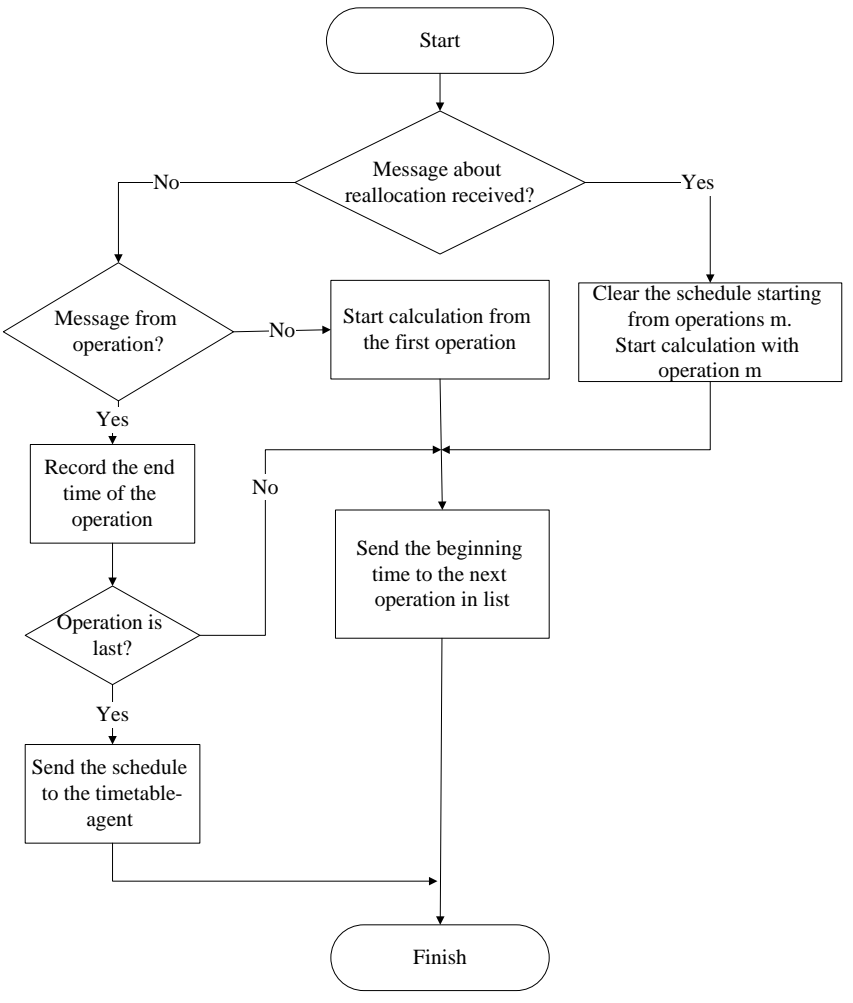

where 


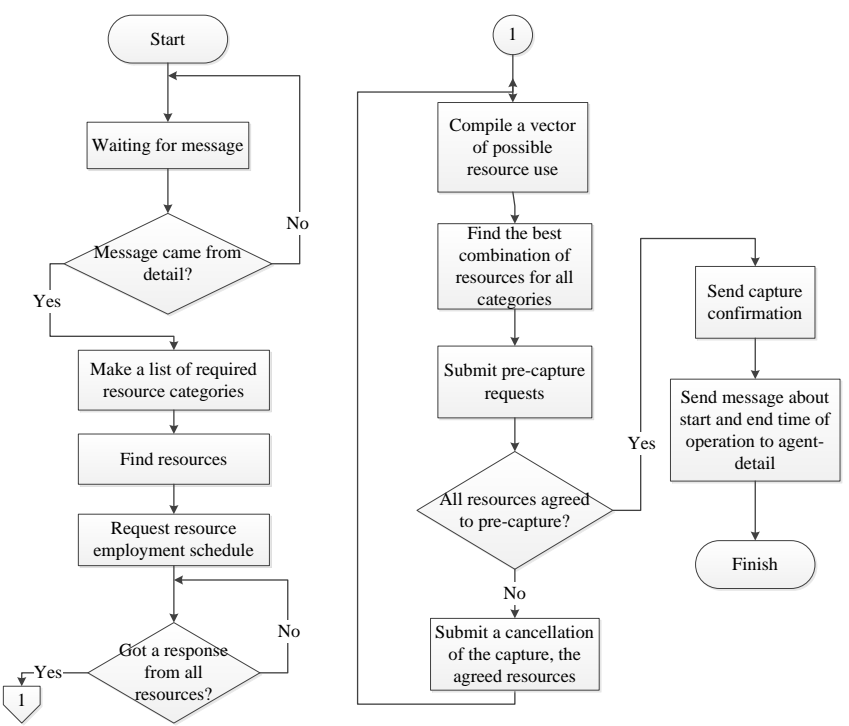

Fig 4. Behavioral algorithm of agent «operation»

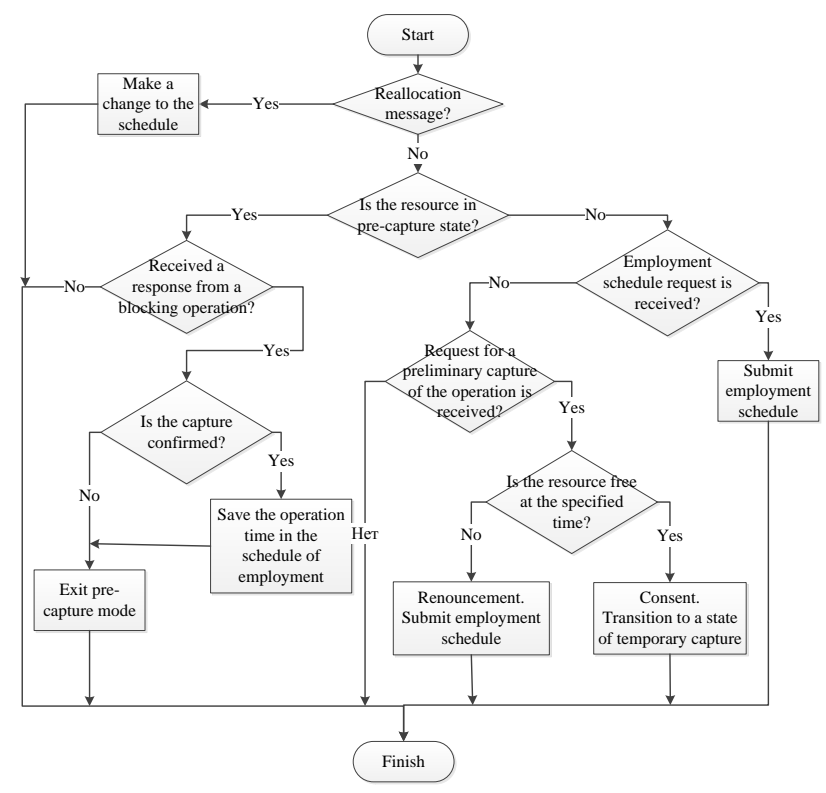

Fig 5. Behavioral algorithm of agent «resource»
The developed algorithms serves as the basis for the software implementation of the decision support system for resource management in manufacturing scheduling.

\section{CONCLUSION}

The paper considers the problem of resource management in manufacturing scheduling. It is suggested to use intelligent data processing technologies for resource management in manufacturing scheduling based on multiagent approach.

The general and behavioral algorithms of agents was developed.

\section{ACKNOWLEDGMENT}

The research is partially supported by grants RFBR 1807-00193-a and 19-07-00895-a.

\section{REFERENCES}

[1] 6 components of Industry 4.0. URL: http://www.plm.pw/2016/09/The-6-Factors-of-Industry-4.0.html

[2] Schwab, K. The Fourth Industrial Revolution. M.: Eksmo, 2016, 208 p. (in Russian)

[3] Huang, T., Yasuda, K.: Comprehensive review of literature survey articles on ERP. Business Process Management Journal 22(1), 2016, pp. 2-32.

[4] Haddara, M., Zach, O.: ERP systems in SMEs: An extended literature review, International Journal of Information Science 2(6), 2012, pp. 106-116.

[5] Gol'fstrim. Production is in focus. Production Planning (in Russian), http://gulfstream-mrp.ru/functions/planning, last accessed 2018/08/03.

[6] MES-system for mechanical engineering PolyPlan (in Russian), http://www.fobos-mes.ru/sistema-polyplan/mes-sistema-dlyamashinostroeniya-polyplan.html, last accessed 2018/08/03.

[7] Skobelev, P.O.: Real-Time Intellectual Resource Management Systems: Principles of Development. Experience of Industrial Implementation and Development Prospects. Information technologies 1, 2013, pp. 1-32 (in Russian).

[8] Kovacs, G., Yussupova, N., Rizvanov, D.: Resource management simulation using multi-agent approach and semantic constraints. Pollack Periodica 12(1), 2017, pp. 45-58.

[9] Yussupova N., Rizvanov D. Decision-Making Support in Resource Management in Manufacturing Scheduling // Proceedings of 18th IFAC Conference onTechnology, Culture and International Stability (TECIS 2018). Volume 51, Issue 30, pp. 544-547. 